\title{
Interannual and Interdecadal Variability of the South Atlantic Convergence Zone*
}

\author{
ANDREW W. Robertson ${ }^{+}$And CARlos R. Mechoso \\ Department of Atmospheric Sciences, University of California, Los Angeles, Los Angeles, California
}

(Manuscript received 7 July 1999, in final form 28 January 2000)

\begin{abstract}
Interannual variations of the summertime (January-March) atmospheric circulation over subtropical South America are examined during the period 1958-97 using the National Centers for Environmental PredictionNational Center for Atmospheric Research reanalysis data. It is found from an empirical orthogonal function analysis that an anomalous upper-tropospheric large-scale stationary eddy in the lee of the Andes tends to accompany a dipole in anomalous vertical motion. An anomalous cyclonic (anticyclonic) eddy accompanies an intensified (diffuse) South Atlantic convergence zone (SACZ), with anomalous descent (ascent) to the southwest. The cold-core equivalent barotropic vertical structure of the anomalous cyclonic eddy and the 200-hPa vorticity balance are both characteristic of a stationary Rossby wave; the tendency for the eddy to be advected downstream by the mean westerlies is compensated by meridional advection of planetary vorticity and stretching associated with vertical motion. The anomalous cyclonic flow at low levels reinforces the thermally direct circulation associated with the SACZ. A weak funneling of submonthly Rossby wave activity into this descent region is also identified.

The interannual time series of the eddy is significantly correlated with north-south dipolar sea surface temperature (SST) anomalies over the southwest Atlantic; one standard deviation 200-hPa wind speed anomalies of up to $5 \mathrm{~m} \mathrm{~s}^{-1}$ are accompanied by SST anomalies of up to $0.3^{\circ} \mathrm{C}$. A near-cyclic 15 -yr component is identified, which the authors corroborate from independent analyses of southwest Atlantic SSTs and river flows; both are found to exhibit very similar oscillatory components. When the SACZ is intensified, the Paraná and Paraguay rivers in southern Brazil tend to swell, while the Uruguay and Negro rivers to the south tend to ebb; this northsouth contrast in streamflow anomalies is most marked on the interdecadal timescale.
\end{abstract}

\section{Introduction}

The South Atlantic convergence zone (SACZ) is a major summertime convective complex that extends southeastward from the primary center of tropical convection over Amazonia. The intensity of the SACZ varies considerably on submonthly (Liebmann et al. 1999) and intraseasonal (Nogués-Paegle and Mo 1997) timescales. In both cases, the variability is characterized by a meridional seesaw in upper-level cloud and precipitation. Drought in southern Brazil is associated with a weakened SACZ on intraseasonal timescales (Casarin and Kousky 1986).

Enhanced convection over the Amazon enhances de-

\footnotetext{
* Institute of Geophysics and Planetary Physics, University of California, Los Angeles, Publication Number 5446.

+ Additional affiliation: Institute of Geophysics and Planetary Physics, University of California, Los Angeles, Los Angeles, California.

Corresponding author address: Dr. Andrew W. Robertson, Department of Atmospheric Sciences, UCLA, 405 Hilgard Avenue, Los Angeles, CA 90095-1565.

E-mail: andy@atmos.ucla.edu
}

scent to the southwest of the heating, as shown by Gandu and Silva Dias's (1998) study of the stationary response to idealized heat sources using simplified models. The addition of a localized SACZ heating was found to further amplify this descent region, leading to a dipole structure in vertical motion with elongated centers aligned from northwest to southeast. The latter resembles the dipoles in cloud cover seen in intraseasonal OLR variations. From this point of view, the dipole structure is primarily determined by Rossby wave dispersion away from the convective region over tropical South America. Liebmann et al. (1999) provide a contrasting viewpoint on submonthly timescales, in which propagating extratropical Rossby waves intensify the SACZ. They find submonthly episodes of enhanced convection within the SACZ to occur along the leading edge of upper-level troughs as they propagate equatorward into the region from the southwest. Kiladis and Weickmann (1992) and Kiladis (1998) have previously identified this type of behavior over the eastern tropical Pacific to be associated with Rossby wave propagation from the North Pacific storm track into the intertropical convergence zone (ITCZ).

The aim of this study is to examine January-March (hereafter JFM) summertime circulation variability over 
southern South America on interannual timescales using the National Centers for Environmental Prediction-National Center for Atmospheric Research (NCEP-NCAR) reanalysis 1958-97 dataset. We examine the possibility of systematic links between Rossby waves east of the Andes, and the variations in intensity of SACZ convection and strength of descending motion to the south. We also examine whether this behavior is linked to anomalies in surface conditions, particularly sea surface temperature (SST) and river flows as representative of integrated precipitation. Our analysis is not restricted to interannual timescales and we extend our scope into the decadal range.

The dataset and methodology are presented in section 2 , and the structure of the leading empirical mode of variability is discussed in section 3 . The vorticity and thermodynamic budgets for a composite interannual event are constructed in section 4, indicating a stationary Rossby wave structure. To assess the role of transient Rossby waves propagating into the SACZ from the extratropics we compute submonthly $E$ vectors in section 5. We examine relationships with SST and riverflows in section 6. A singular spectrum analysis (SSA) is made to examine the power spectrum of variability, from which we identify a marked 15-17-yr timescale in the strength of the SACZ and the SST anomalies over southwest Atlantic, as well as streamflow anomalies. Our results are summarized and discussed in section 7 .

\section{Data and methodology}

We use the 1958-97 NCEP-NCAR Reanalysis dataset (Kalnay et al. 1996), given on a $2.5^{\circ}$ grid, from which we form 40 JFM averages. The quality of the reanalysis dataset has been shown to be adequate in several studies of tropical and subtropical intraseasonal variability (Kiladis and Weickmann 1997; Liebmann et al. 1999). Figure 1 shows the southern summer (JFM) 40-yr average of the wind field at 200 (Fig. 1a) and 850 $\mathrm{hPa}$ (Fig. 1b). The Bolivian anticyclone and downstream trough are clearly present at $200 \mathrm{hPa}$. At low levels, the main features are the subtropical anticyclone over the South Atlantic and the monsoonal easterly inflow into northeastern South America. Superposed on the wind fields in Fig. 1 are the reanalysis 500-hPa omega field in Fig. 1a and the 1978-96 outgoing longwave radiation (OLR) field from the Climate Diagnostics Center (CDC; Liebmann and Smith 1996) in Fig. 1b. These two independent measures of vertical motion exhibit broadly similar patterns with continental ascent and maritime subsidence, lending credence to the quality of the reanalysis mean divergent circulation. Indeed, the SACZ is more sharply defined in the omega field, near $30^{\circ} \mathrm{S}$, $40^{\circ} \mathrm{W}$.

Our method of investigation is based on standard empirical orthogonal function (EOF) analysis of both wind components at $200 \mathrm{hPa}$ combined into a single vector field, with gridpoint values of each component nor- a) $200 \mathrm{hPa}$ Wind \& $500 \mathrm{hPa}$ Omega

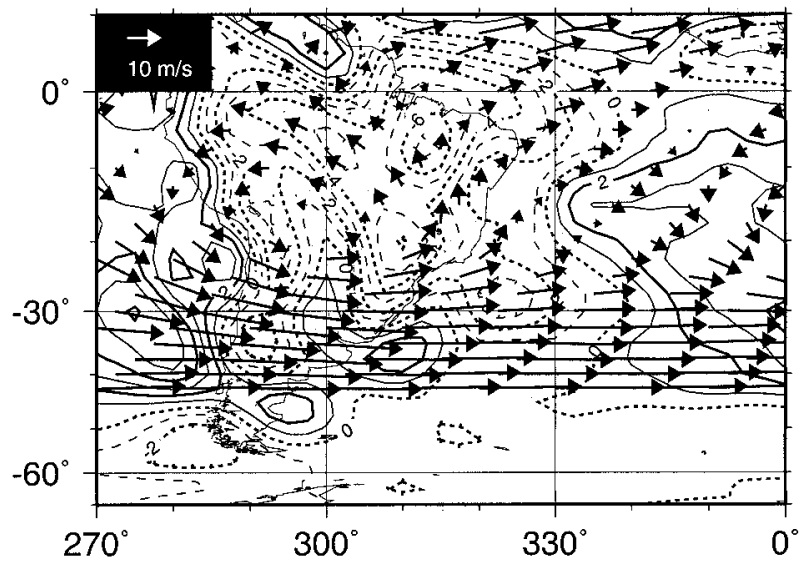

b) $850 \mathrm{hPa}$ Wind \& CDC OLR

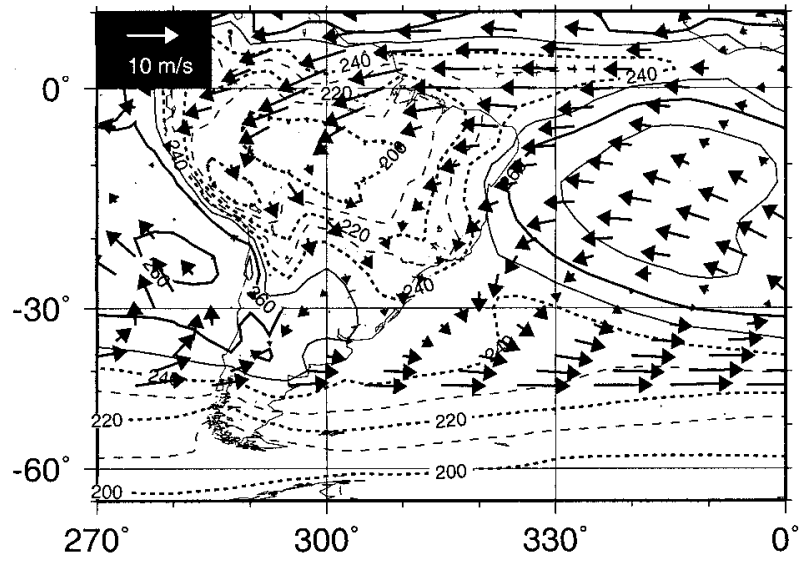

FIG. 1. Climatological mean Jan-Mar wind vectors at (a) 200 and (b) $850 \mathrm{hPa}$, with contours of (a) 500-hPa omega (contour interval: $1 \times 10^{-2} \mathrm{~Pa} \mathrm{~s}^{-1}$, negative contours dashed), and (b) OLR (contour interval: $10 \mathrm{~W} \mathrm{~m}^{-2}$, values $<250 \mathrm{~W} \mathrm{~m}^{-2}$ dashed). The wind and omega fields are from the NCEP-NCAR reanalysis 1958-97, and the OLR is from CDC 1978-96. The wind vectors are suppressed south of $45^{\circ} \mathrm{S}$.

malized by their respective standard deviations. We choose $200-\mathrm{hPa}$ wind rather than the reanalysis omega field because the former is based on a directly observed quantity and is characterized by larger spatial scales than omega. Nevertheless, the two quantities are closely related dynamically in the Tropics and subtropics (Sardeshmukh and Hoskins 1987). To focus on off-equatorial South American circulation variability we select the domain $50^{\circ}-10^{\circ} \mathrm{S}$ and $70^{\circ}-20^{\circ} \mathrm{W}$ for the EOF analysis. The principal component (PC) timeseries of the leading EOF is used to construct regression maps and composite anomalies of other variables. For SST, we use the GISST dataset (Rayner et al. 1995). The riverflows considered are from the Paraná, Paraguay, Uruguay, and Negro rivers 1911-93, whose monthly dataset 
a) EOF $1(23 \%)$

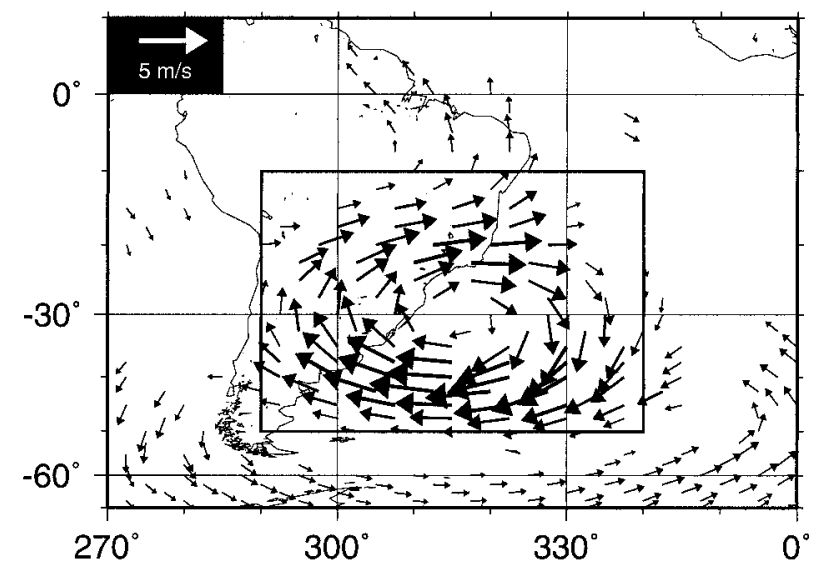

b) EOF $2(16 \%)$

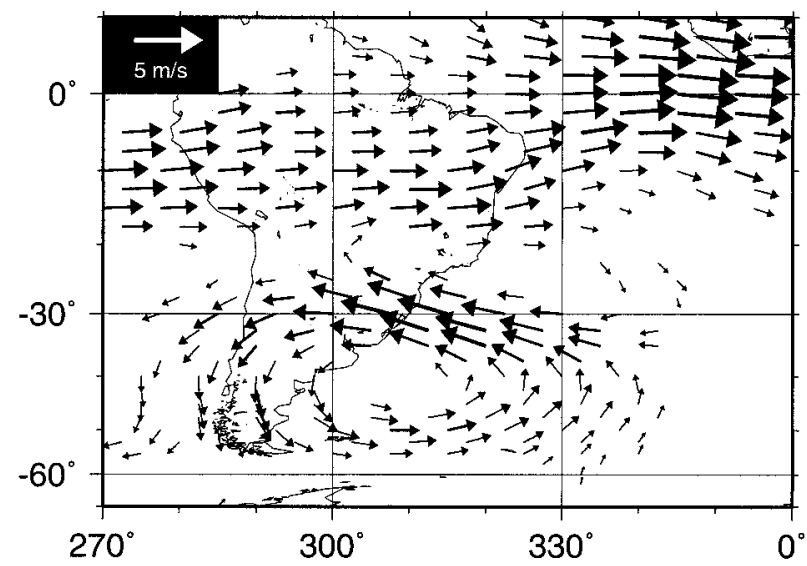

FIG. 2. Regression maps of 200-hPa winds with unfiltered (a) PC 1 and (b) PC 2. Magnitudes correspond to one standard deviation of the PC. The domain of the EOF analysis is indicated by the box in (a). Only vectors whose correlations with the respective PC pass a two-tailed Student t-test at the $95 \%$ level are plotted, with the number of effective degrees of freedom estimated locally at each grid point from the decorrelation times of the $\mathrm{PC}$ and the wind time series at that grid point (Davis 1976).

is described in Genta et al. (1998) and Robertson and Mechoso (1998).

\section{Modal structure}

The leading EOF of 200-hPa wind accounts for $23.4 \%$ of the interannual variance, with the second mode accounting for $16.2 \%$. Figure 2 shows the two leading EOFs in terms of regression maps with the respective PC; only statistically significant vectors are plotted. Note that the maps in Fig. 2 are displayed in the same domain used in Fig. 1, which extends beyond the domain of the EOF calculation (indicated by the box in Fig. 2a). The first EOF (Fig. 2a) describes a strong isolated eddy centered just south of the SACZ, with a half-wave- length of about $30^{\circ}$ in both longitude and latitude; this corresponds approximately to zonal wavenumber 6 . Wind amplitudes exceed several meters per second for a one standard deviation anomaly. The location and scale of the eddy resemble the stationary Rossby wave found during January 1979 by Kalnay et al. (1986), although that structure had a slightly smaller scale (zonal wavenumber 7 ), was situated about $10^{\circ}$ farther to the east, and was more wavetrainlike. Aside from some indication of poleward propagation, no significant remote teleconnections are evident, and this is also true globally.

The second EOF (Fig. 2b) exhibits strong zonal wind anomalies in the equatorial band, characteristic of the Walker circulation; there are also wind anomalies near $30^{\circ} \mathrm{S}$. Enlarging the domain to encompass all of South America $\left(60^{\circ} \mathrm{S}-10^{\circ} \mathrm{N}, 90^{\circ}-30^{\circ} \mathrm{W}\right)$ causes the ordering of the leading two EOFs to switch, but their spatial structures remain similar, especially that of Fig. 2a. The structure of EOF 1 seen in Fig. $2 \mathrm{a}$ is insensitive to rotating the leading four PCs using a varimax rotation in the larger domain. A very similar structure is also obtained when using December-February averages in place of JFM, or using the nonnormalized wind components. The wind anomalies in EOF 2 near $30^{\circ} \mathrm{S}$ are less robust to these tests.

The three-dimensional structure of the leading EOF is shown in Fig. 3 using regression maps of $500-\mathrm{hPa}$ omega (Fig. 3a) and 850-hPa wind and temperature (Fig. $3 b)$; similar results are obtained when using the 197896 OLR time series in place of the reanalysis omega field, confirming the adequacy of the latter. The vertical motion field shows a dipole pattern along the eastern coast of South America; it is similar to the structure of the second interannual EOF of the omega field itself over the domain $60^{\circ} \mathrm{S}-10^{\circ} \mathrm{N}, 90^{\circ}-30^{\circ} \mathrm{W}$ (not shown). Anomalous ascent coincides with the mean SACZ position (Fig. 1b); thus Fig. 3 primarily reflects variations in intensity of the SACZ. The localized region of strong anomalous descent over the subtropical plains to the southwest also coincides with the region of mean descent in Fig. 1, although the latter is weak. Composites of total omega for years where the amplitude of PC 1 exceeds plus or minus one standard deviation were also constructed (not shown). Over the SACZ region, the positive composite looks similar to the regression map in Fig. 3a, while the negative composite shows broad but weaker ascent over most of southeastern South America, without a pronounced SACZ.

The anomalous $200-\mathrm{hPa}$ cyclonic circulation of EOF 1 (Fig. 3a) is centered to the southwest of the region of midlevel anomalous ascent. This configuration is also similar to the one found on intraseasonal timescales by Liebmann et al. (1999), except that their intraseasonal trough is tilted from northwest to southeast. There is also a cyclonic circulation at $850 \mathrm{hPa}$ (Fig. 3b), but it has a shorter zonal length scale than at upper levels. This low-level circulation coincides with cold temper- 
a) $500 \mathrm{hPa}$ Omega \& $200 \mathrm{hPa}$ Wind

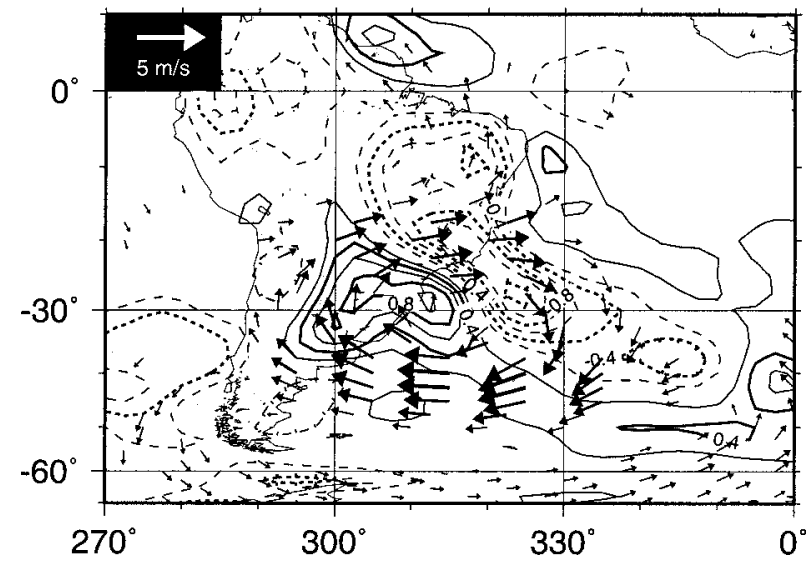

b) $850 \mathrm{hPa}$ Temperature \& Wind

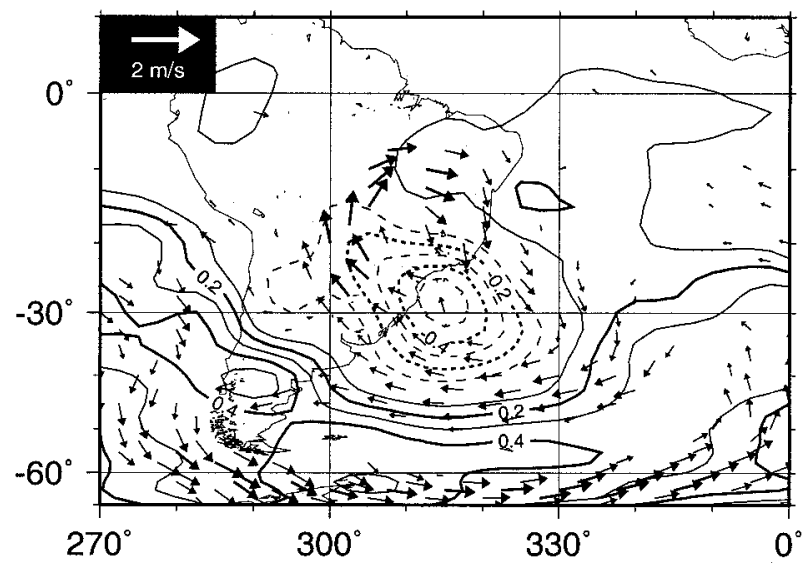

FIG. 3. Regression maps of PC 1 with (a) 200-hPa winds and 500hPa omega (contour interval: $0.2 \times 10^{-2} \mathrm{~Pa} \mathrm{~s}^{-1}$ ), and (b) $850-\mathrm{hPa}$ winds and temperature (contour interval: $0.1 \mathrm{~K}$ ). Magnitudes correspond to one standard deviation of PC 1. Zero contour omitted and negative dashed.

ature anomalies. The vertical structure of the leading EOF is, therefore, near-equivalent barotropic south of $20^{\circ} \mathrm{S}$, characteristic of a stationary Rossby wave. To the north, the vertical structure becomes markedly baroclinic. Warm anomalies are found farther south of $50^{\circ} \mathrm{S}$.

A global correlation map with $500-\mathrm{hPa}$ omega (not shown) exhibits no significant relationship with the South Pacific convergence zone (SPCZ), in contrast to the one found on intraseasonal timescales (Nogués-Paegle and Mo 1997).

\section{Vorticity and thermodynamic budget}

The anomalous upper-level eddy identified in the previous section is clearly not in a simple Sverdrup vorticity balance with the anomalous vertical motion field. A Sverdrup balance is typical of convective heating in the
Tropics, in which the primary balance is between poleward advection of planetary vorticity and stretching of vortex tubes by ascent (Gill 1980). Gandu and Silva Dias (1998) found that such a balance also holds in idealized Amazonia-SACZ numerical experiments. Horizontal advection of relative vorticity can be expected to be important in our case since the vertical motion dipole in Fig. 3a extends poleward of $30^{\circ} \mathrm{S}$ (Hoskins and Karoly 1981; Rodwell and Hoskins 1996).

To quantify the main contributors to the 200 -hPa vorticity budget on interannual timescales, we approximate the steady-state vorticity equation by its linearized expression about the climatological time mean flow:

$$
\overline{\mathbf{v}} \cdot \boldsymbol{\nabla} \zeta^{\prime}+\mathbf{v}^{\prime} \cdot \boldsymbol{\nabla} \bar{\zeta}=\left(\boldsymbol{\nabla} \cdot \mathbf{v}^{\prime}\right) \bar{\zeta}+R_{s},
$$

where $\zeta$ is the absolute vorticity and $\mathbf{v}$ is the horizontal wind vector. Here overbars denote 40 -summer averages and primes denote interannual anomalies. The residual $R_{\zeta}$ contains all other terms, including nonlinear terms, the effects of the time mean divergence, and subseasonal transients. The nonlinear terms were found to be comparatively small throughout this section. We define anomalies by a composite of years in which deviations of PC 1 exceed plus or minus one standard deviation. Each term in (1) was then composited by subtracting the resulting six negative years from the four positive ones.

Figure 4 shows the composite positive-minus-negative anomalies, expressed as vorticity tendencies corresponding to an intensified SACZ. The two advection terms are large and tend to compensate each other, while the stretching term is generally smaller. This is characteristic of a stationary Rossby wave. The anomalous negative vorticity maximum tends to be advected downstream by the strong mean westerlies around $30^{\circ} \mathrm{S}$ (Fig. $4 \mathrm{~b}$ ), while the resulting vorticity tendencies are largely offset by the advection of planetary vorticity by the anomalous eddy itself (Fig. 4c). Nonetheless, the stretching term is nonnegligible (Fig. 4a).

The thermodynamic equation can be approximated in a similar fashion:

$$
\overline{\mathbf{v}} \cdot \nabla T^{\prime}+\mathbf{v}^{\prime} \cdot \nabla \bar{T}-S_{P} \omega^{\prime}=R_{T},
$$

where $T$ is temperature, $S_{P}$ is a constant static stability, $\omega=d p / d t$, and $R_{T}$ is the residual that includes the diabatic heating. Figure 5 illustrates the four terms in (2) at $850 \mathrm{hPa}$, with $S_{P}=8 \times 10^{-4} \mathrm{~K} \mathrm{~Pa}^{-1}$. The mean winds circulating around the South Atlantic subtropical anticyclone (Fig. 1b) tend to advect warmer air into the northern part of the SACZ (Fig. 5a). Low-level anomalous northwesterly winds (Fig. 3b) tend to advect warm moist air from Amazonia into the southern part of the SACZ (Fig. 5b, near $30^{\circ} \mathrm{S}, 30^{\circ} \mathrm{W}$ ), while cool air is advected into the region of descent (near $30^{\circ} \mathrm{S}, 60^{\circ} \mathrm{W}$ ). Thus, both components of the linearized horizontal advection (Figs. 5a and 5b) act to offset the temperature changes associated with the anomalous thermally direct circulation (Fig. 5c). Maintenance of the ascent by hor- 


\section{a) Stretching}

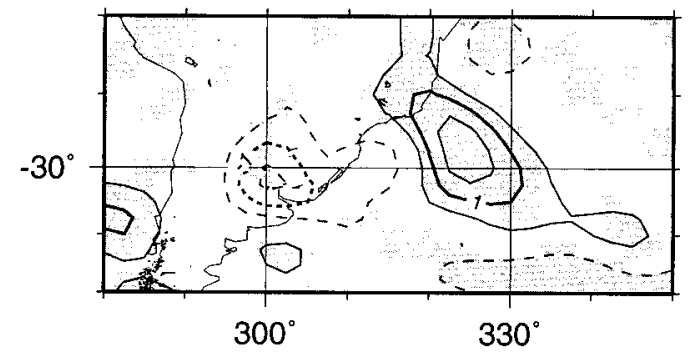

c) Sverdrup Advection

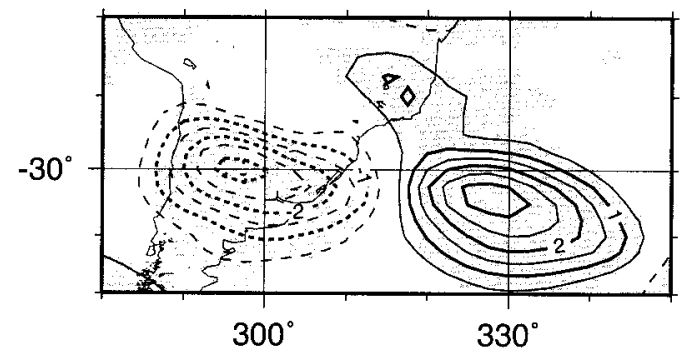

b) Mean-wind Advection

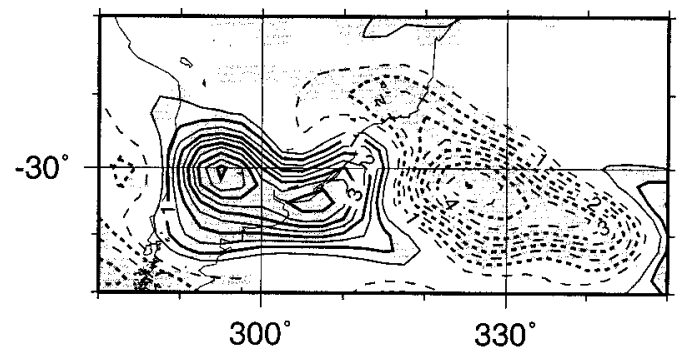

d) Residual

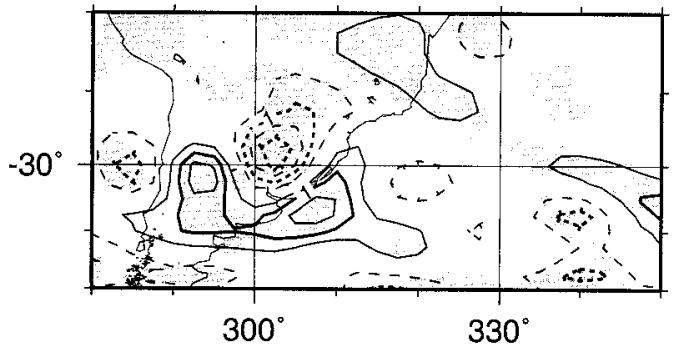

FIG. 4. Terms in the linearized vorticity budget at $200 \mathrm{hPa}$ for the anomalously intense SACZ composite (see text). (a) $\left(\boldsymbol{\nabla} \cdot \mathbf{v}^{\prime}\right) \bar{\zeta}$, (b) $-\overline{\mathbf{v}} \cdot \boldsymbol{\nabla} \zeta^{\prime}$, (c) $-\mathbf{v}^{\prime} \cdot \nabla \bar{\zeta}$, and (d) $R_{\mathrm{s}}$. The contour interval is $0.5 \times 10^{-10} \mathrm{~s}^{-2}$; zero contour omitted and negative dashed. Shaded areas are significant at the $95 \%$ confidence level, from a Student's two-tailed $t$-test with nine degrees of freedom.

izontal moisture and temperature advection is a hallmark of subtropical convergence zones such as the SACZ, the SPCZ, or the Biau frontal zone (Kodama 1992, 1993). The tendency for horizontal cold advection to offset descent-induced adiabatic warming (Figs. 5b and 5c) has also been found to operate over the Sahara desert, as a response to the Asian monsoon (Rodwell and Hoskins 1996). The residual in Fig. 5d includes the diabatic heating and the influence of spatial variations in $S_{P}$; it is locally large, particularly over the Bolivian altiplano, where the topography lies above the 850 -hPa level of analysis.

\section{The role of transients}

Liebmann et al. (1999) have shown that submonthly episodes of enhanced convection within the SACZ tend to occur along the leading edge of upper-level troughs propagating equatorward into the region from the extratropics. They speculate that interannual variability in this extratropical wave activity could be responsible for year-to-year fluctuations in the SACZ, as was found by Kiladis (1998) for the ITCZ over the eastern tropical Pacific.

To explore whether this speculation is supported by our data, submonthly $E$ vectors (Hoskins et al. 1983) are plotted in Fig. 6 using the same filter as Liebmann et al. (1999); contours of JFM mean omega are superposed to identify the convergence zones. The climatological JFM distribution (Fig. 6a) shows the general equatorward Rossby wave dispersion associated with the summertime midlatitude storm track. There is some indication of a funneling of Rossby wave activity into the region to the southwest of the SACZ. The distribution is similar to the one constructed for the period December-February 1979-96 by Liebmann et al. (1999), although the propagation into the SACZ itself found in their study is not reproduced here.

Figure $6 \mathrm{~b}$ shows the $E$ vector composite for interannual intensifications of the SACZ, constructed in a similar fashion to the composites in Figs. 4 and 5. The main deviation from climatology is the weakening of equatorward propagation, especially to the west of the Andes. There is an indication of a northward extension of wave activity into the region of enhanced descent to the southwest of the SACZ, consistent with Liebmann et al.'s (1999) conjecture.

\section{Relationships with SST, river flows, and interdecadal variability}

\section{a. Interannual SSTS}

To investigate possible links with SST we compute maps of its regression with the two leading 200-hPa 


\section{a) Mean-wind Advection}

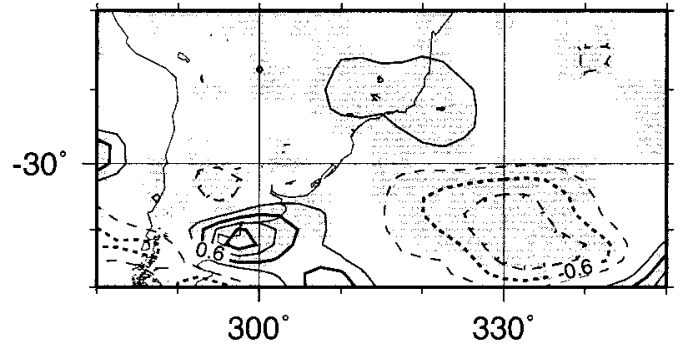

c) Omega * Sp

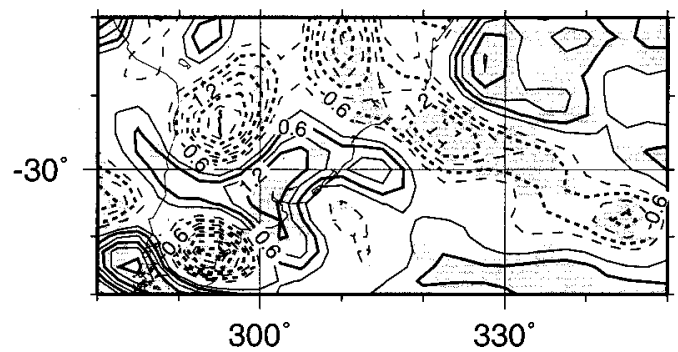

b) Anomalous-wind Advection

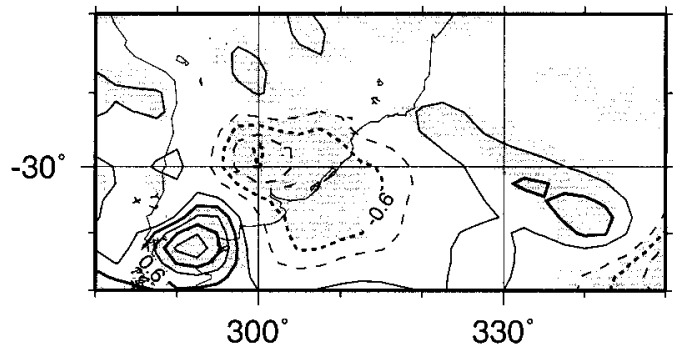

d) Residual

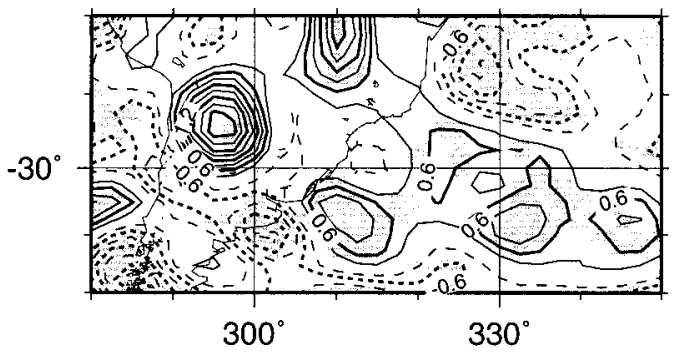

FIG. 5. Terms in the linearized quasigeostrophic thermodynamic equation at $850 \mathrm{hPa}$ for the anomalously intense SACZ composite (see text): (a) $-\overline{\mathbf{v}} \cdot \nabla T^{\prime}$, (b) $-\mathbf{v}^{\prime} \cdot \nabla \bar{T}$, (c) $S_{P} \omega^{\prime}$, and (d) $R_{T}$. The contour interval is $0.3 \times 10^{-5} \mathrm{~K}$ $\mathrm{s}^{-1}$; zero contour omitted and negative dashed. Shaded areas are significant at the $95 \%$ confidence level, from a two-tailed Student's $t$-test with nine degrees of freedom.

PCs. Figure 7a show significant correlations with a dipole pattern over the southwest Atlantic, characterized by centers at about $20^{\circ}$ and $45^{\circ} \mathrm{S}$. The nodal line of the dipole is near $40^{\circ} \mathrm{S}$, which coincides approximately with the confluence region of the (southward) Brazil and (northward) Malvinas ocean currents (Olson et al. 1988). There are no significant correlations with El Niño SST anomalies, nor with equatorial or North Atlantic SSTs. Figure 7b confirms that the second mode is associated with El Niño, with large SST regression values over the eastern tropical Pacific. The second mode also exhibits a positive SST anomaly over the southwest Atlantic.

\section{b. Interdecadal variability of $P C 1$ and SSTs}

The time series of PC 1 is plotted in Fig. 8. Also plotted is the sum of the leading oscillatory pair of reconstructed components (RCs) from an SSA (Vautard et al. 1992; Dettinger et al. 1995) of PC 1, with a window width of $M=20 \mathrm{yr}$. The RCs are narrowband dataadaptive filters that efficiently capture phase-modulated oscillations. The filtered series has a nominal period of $14.7 \mathrm{yr}$ and accounts for $24.5 \%$ of the variance of PC 1. It is robust to different choices of the spectral window and is statistically significant against a red noise null hypothesis at about the $80 \%$ level (Allen and Smith
1996). In view of the shortness of the time series, this result indicates at least a substantial interdecadal variability.

To investigate this interdecadal timescale further, we turn first to the longer time series of GISST data that exhibits statistically significant correlations with PC 1 over the southwest Atlantic in Fig. 7a. We construct an SST index by averaging over the region $60^{\circ} \mathrm{W}-0^{\circ}$ and $20^{\circ}-30^{\circ} \mathrm{S}$ for the entire 1903-94 GISST dataset using JFM means. The SST index is multiplied by -1 to match the sign of PC 1 (Fig. 7). Applying SSA to this series identifies an oscillatory RC pair (RCs 2 and 3) with the same nominal period of $14.7 \mathrm{yr}$ as RCs $1-2$ of PC 1, and with a phase that also closely matches the latter (see Fig. 10, below). It accounts for $17.8 \%$ of the variance and is significant at the $80 \%$ level against a null hypothesis of red noise. The leading RC of the SST time series is an upward trend that accounts for $28.0 \%$ of the variance. The SSA window width used here is $M=25 \mathrm{yr}$, compared to $M=20$ used for the shorter reanalysis time series. The results are again found to be insensitive to the precise choice of window, but we use different window widths here to demonstrate that the match in period is not a trivial function of $M$. The multitaper method applied to the GISST time series corroborates the SSA result, yielding a peak at $17.7 \mathrm{yr}$ that 
a) JFM Mean

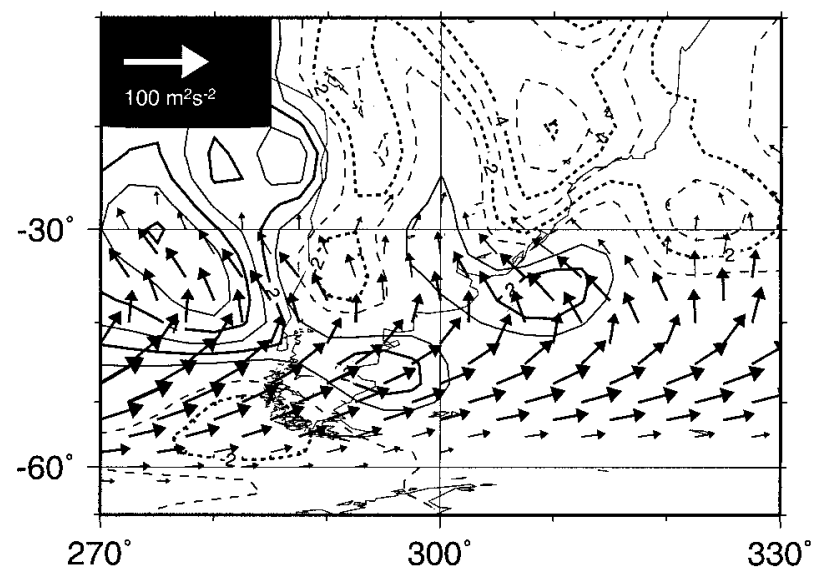

b) Anomaly Composite

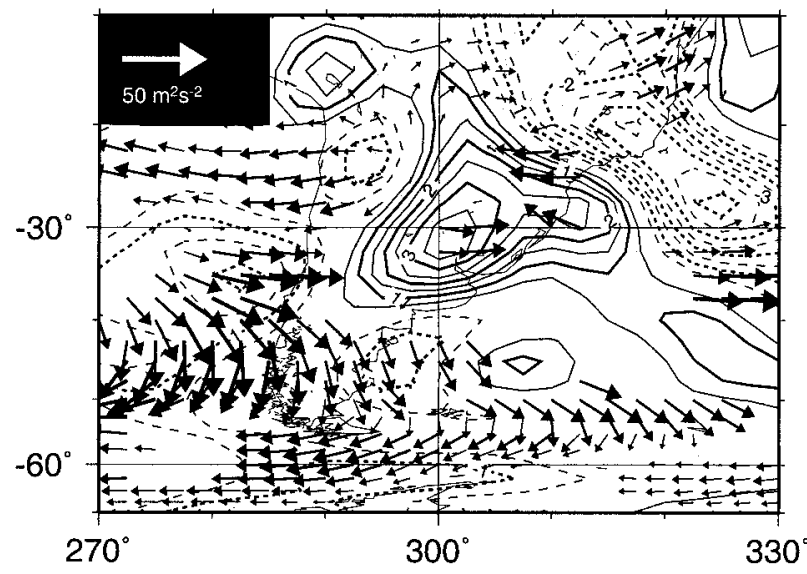

FIG. 6. Submonthly 200-hPa $E$ vectors with contours of 500-hPa omega, both for JFM. (a) Climatology and (b) anomalously intense (positive-minus-negative) SACZ composite (see text). The contour interval of omega is $1 \times 10^{-2} \mathrm{~Pa} \mathrm{~s}^{-1}$ in (a) and $0.5 \times 10^{-2} \mathrm{~Pa} \mathrm{~s}^{-1}$ in (b). In (b), only vectors that are statistically significant at the $95 \%$ confidence level are plotted, from a two-tailed Student's $t$-test with nine degrees of freedom. Zero contour omitted and negative dashed.

is statistically significant at the $95 \%$ level against a red noise null hypothesis using the test of Mann and Lees (1996).

The reanalysis and GISST datasets are not strictly independent because observed SSTs are used to drive the reanalysis assimilation model, with the GISST dataset itself being used prior to 1982 (Kalnay et al. 1996). The precise match in period and phase between the interdecadal components found in the two datasets may be fortuitous, but it does suggest that ocean-atmosphere interaction is important. Figure 9 shows a global map of the correlations between the interdecadal component (RCs 2-3) of South Atlantic SST constructed above and JFM means of SST at each grid point. There is a large area of significant correlation values over the subtropical southwest Atlantic, but no sign of the dipole in SSTs seen in the unfiltered correlations with the 200-hPa circulation PC 1 (Fig. 3a). No significant remote correlations are apparent.

\section{c. River flows}

Precipitation over southeastern South America is strongly influenced by El Niño (Ropelewski and Halpert 1987, 1996; Pisciottano et al. 1994), while streamflows show both El Niño and near-decadal cycles (Robertson and Mechoso 1998). To examine further the realism of the interdecadal cycle and its importance for hydrology, we have examined the streamflows of the Paraná, Paraguay, Uruguay, and Negro Rivers in the Rio de la Plata basin. Flow in rivers is a measure of precipitation in the river basins, although the precise relationship can be made complex by influence of processes such as soil moisture, snowmelt, etc. The Uruguay and Negro drain a relatively small catchment $\left(0.5 \times 10^{6} \mathrm{~km}^{2}\right)$, situated mostly within Uruguay and southeastern Brazil $\left(25^{\circ}-\right.$ $\left.35^{\circ} \mathrm{S}\right)$. The Paraná and Paraguay drain a much larger area $\left(2.1 \times 10^{6} \mathrm{~km}^{2}\right)$, mostly to the north, bounded approximately by the Andes to the west and the Atlantic Ocean to the east, extending northward to near $15^{\circ} \mathrm{S}$. More details of the drainage basins and measuring stations are given in Genta et al. (1998) and Robertson and Mechoso (1998).

Streamflow composites were made for one-sigma excursions of PC 1 as well as for the 15-yr oscillatory RCs of both winds and SSTs, using JFM averages for the period 1911-93; the results are tabulated in Table 1. There is a marked tendency for a north-south divide in streamflow anomalies, with an intensified SACZ associated with enhanced streamflows to the north (the Paraná and Paraguay) and diminished flows to the south (the Uruguay and Negro). This pattern is especially clear in the 15-yr filtered component of PC 1. Although the number of statistically significant anomalies is limited, all the significant deviations (in bold) conform to this north-south divide.

Some of the largest anomalies are found in the Uruguay river, whose drainage basin is situated well to the south of the SACZ. These river flow anomalies are consistent with a modulation in the strength of the southward low-level jet (LLJ) east of the Andes near $60^{\circ} \mathrm{W}$, and the implied anomalies in moisture transport from Amazonia (Nogués-Paegle and Mo 1997; Li and Le Treut 1999). In Fig. 3b, an intensified (weakened) SACZ is associated with a weak (strong) LLJ, which would tend to transport less (more) moisture into the Uruguay river basin. The importance of the LLJ is further suggested by the tendency for streamflow anomalies to be stronger and more statistically significant in the weak SACZ (i.e., strong LLJ) composite in Table 1.

Robertson and Mechoso (1998) examined the spectra of the combined annual flows of the Paraná-plus-Paraguay and Uruguay-plus-Negro Rivers. No anomalous power was found near $15 \mathrm{yr}$. However, Table 1 indicates 
a) EOF $1(23 \%)$

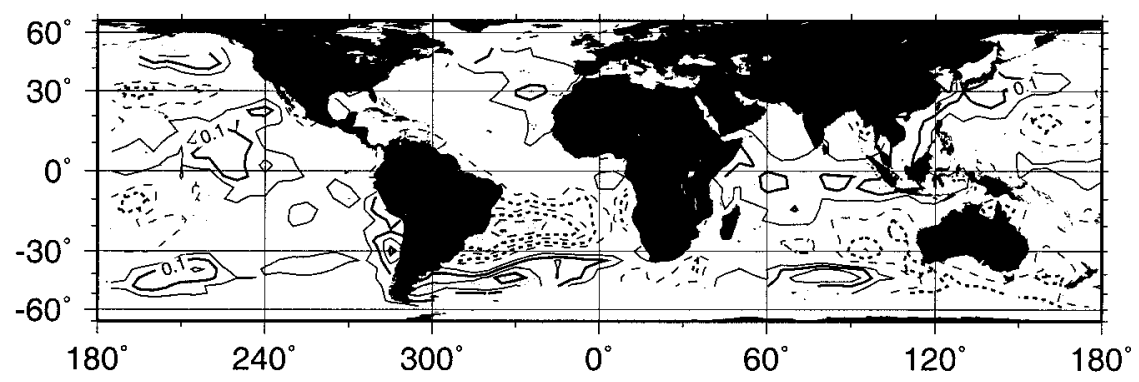

b) EOF $2(16 \%)$

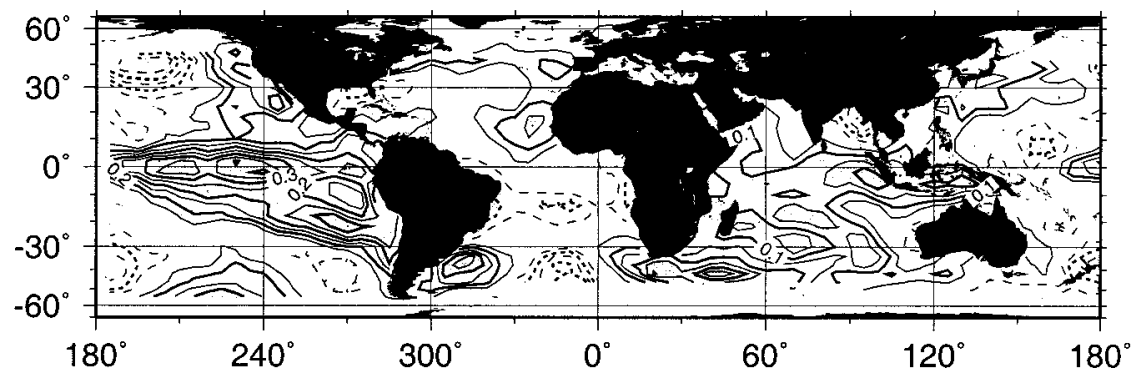

FIG. 7. Regression maps of SST with (a) PC 1 and (b) PC 2. The contour interval is $0.05 \mathrm{~K}$, with the zero contour omitted and negative ones dashed. The shading denotes grid points whose associated correlations are significant at the $95 \%$ level, from a two-tailed Student's $t$-test with the number of degrees of freedom estimated on a pointwise basis as in Fig. 2.

that it is the north-south gradient in streamflow anomalies that is related to SACZ variations. We have, therefore, computed an SSA spectrum of the north-south streamflow difference given by the linear combination (Paraná + Paraguay) - (Uruguay + Negro) of JFM mean river flows, where each river was prenormalized by its standard deviation. Reconstructed components

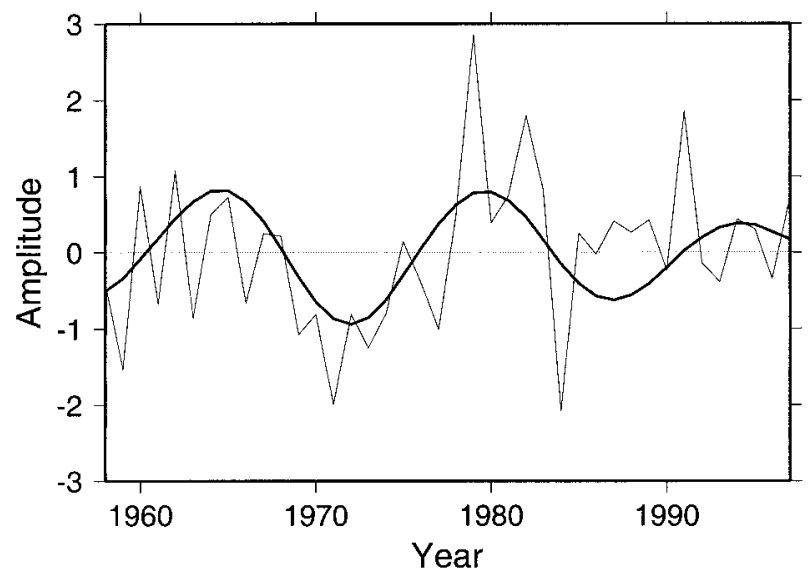

FIG. 8. Time series of PC 1 (light curve) and RCs 1-2 (heavy curve). The latter was constructed using an SSA with a window of $M=20 \mathrm{yr}$; the filtered series has a period of $14.7 \mathrm{yr}$ and accounts for $24.5 \%$ of the variance. The units of the ordinate are standard deviations of PC 1. Years on the abscissa denote the JFM season.
2-3 are found to form an oscillatory pair with a nominal period of $17.5 \mathrm{yr}$, accounting for $14.2 \%$ of the variance, which is significant against red noise at the $90 \%$ confidence level. A window of $M=35 \mathrm{yr}$ was used in this case, to separate the interdecadal component from strong quasi-biennial variability.

Figure 10 illustrates the reconstructed interdecadal components of PC 1, SST, and river flows, using an arbitrary ordinate scale. The phase coherence of the three series since about 1970 is striking. A unit streamflow anomaly amplitude in Fig. 10 corresponds to a 6 $\mathrm{km}^{3}$ per 3-month season difference between the river pairs. The oscillation appears most intense since about 1950. The river data are likely to be more reliable than SST during the first half of the century and the cycle is indeed stronger in the rivers then.

\section{Summary and discussion}

\section{a. Summary}

We have shown that the interannual circulation variability over southern South America during summer is dominated by a localized equivalent barotropic eddy, whose center lies between the SACZ to the northeast and the localized region of mean descent to the southwest. Anomalous cyclonic (anticyclonic) rotation accompanies an intensified (diffuse) SACZ, with anomalous descent (ascent) to the southwest. The 200-hPa 


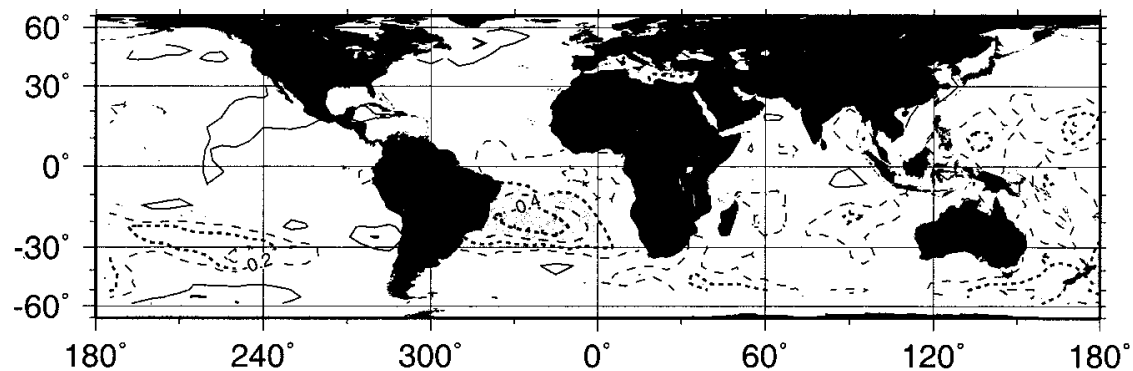

FIG. 9. Correlation map of SST with the interdecadal South Atlantic SST index in Fig. 10. The contour interval is 0.1 , with the zero contour omitted. The $95 \%$ significance region is shaded, derived as in Fig. 2.

vorticity budget is characteristic of a stationary Rossby wave, with advection of anomalous vorticity by the mean subtropical jet tending to balance anomalous advection of planetary vorticity and vortex tube-stretching/compression. At low levels, anomalous thermal advection tends to reinforce the anomalous thermally direct circulation. These interannual anomalies are accompanied by statistically significant anomalies in SST over the southwest Atlantic that take the form of a zonally elongated north-south dipole with the nodal line near $40^{\circ} \mathrm{S}$.

We find independent evidence of an interdecadal component with a $15-17-\mathrm{yr}$ period in PC 1 of the $200-\mathrm{hPa}$ wind and SSTs over the southwest Atlantic between $20^{\circ}$ and $30^{\circ} \mathrm{S}$, as well as in the difference of river discharge between Paraná/Paraguay and Uruguay/Negro rivers. This north-south difference in streamflow anomalies is consistent with the dipolar nature of the atmospheric vertical motion anomalies, with higher streamflows to the north coinciding with years in which the SACZ is intensified, and vice versa.

\section{b. Discussion}

The circulation that dominates interannual variability over the SACZ region has the characteristics of an iso-

TABLE 1. Composite JFM streamflow anomalies $\left(\mathrm{km}^{3} \mathrm{month}^{-1}\right)$ keyed onto PC 1 and the filtered 15-yr RC time series of PC 1 and GISST. Strong (weak) SACZ refers to a one standard deviation positive (negative) deviation of the respective time series. Bold entries are statistically significant at the $95 \%$ level, according to a two-sided Student's $t$-test.

\begin{tabular}{llcc}
\hline \hline & & Strong SACZ & Weak SACZ \\
\hline PC 1 & Negro & -0.57 & $\mathbf{1 . 0 2}$ \\
& Uruguay & $-\mathbf{4 . 4 7}$ & $\mathbf{5 . 5 9}$ \\
& Paraguay & -1.40 & 0.60 \\
Filtered PC 1 & Paraná & -2.34 & -3.70 \\
& Negro & -0.14 & 0.38 \\
& Uruguay & -1.39 & 1.58 \\
Filtered GISST & Paraguay & 0.54 & -1.26 \\
& Paraná & 0.93 & $\mathbf{- 5 . 2 2}$ \\
& Negro & 0.15 & $\mathbf{0 . 2 1}$ \\
& Uruguay & -0.82 & $\mathbf{2 . 1 9}$ \\
& Paraguay & 0.77 & 0.00 \\
& Paraná & 1.31 & $\mathbf{- 4 . 4 1}$ \\
\hline
\end{tabular}

lated stationary Rossby wave. Interannual variations in the low-level thermal advection field act to offset the temperature changes associated with anomalous adiabatic ascent and descent, so that the anomalous thermally direct circulation must strengthen in order to balance a given diabatic heating. This is one of the hallmarks of mean ascent in subtropical convection zones, together with the low-level advection of moisture (Kodama 1992, 1993). Rodwell and Hoskins (1996) have also found this balance to characterize the mean descent over the Sahara Desert, which they suggest is partially forced by the Asian monsoon. They find an important orographic component that may have a counterpart here associated with the Andes.

The leading EOF discussed in this study is of arbitrary sign and can be equally be interpreted as an anticyclonic eddy/weakened SACZ. However, the amplitude of the anomalies in omega (Fig. 3a) can approach that of the mean (Fig. 1a). Composites of total fields for the extreme phases of PC 1 (not shown) indicate that the positive phase represents an intensified SACZ with a lo-

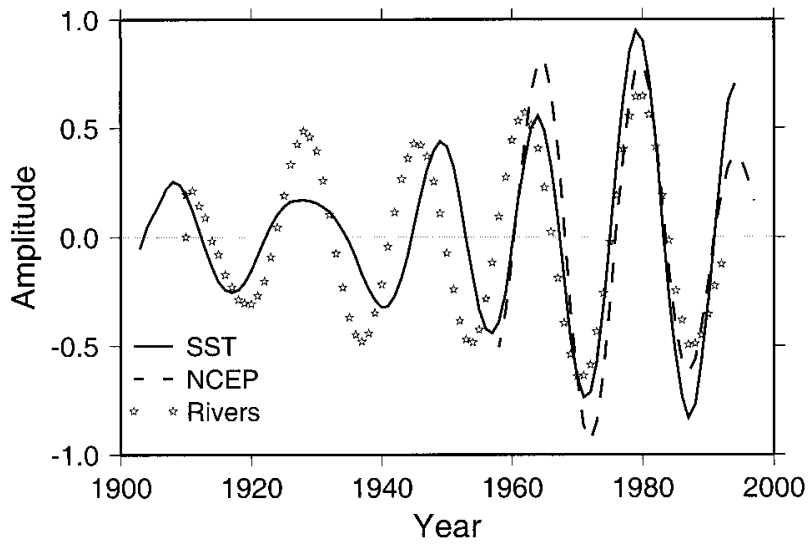

FIG. 10. Filtered time series of PC 1 (solid), SSTs averaged over the southwest Atlantic $\left(20^{\circ}-30^{\circ} \mathrm{S}, 60^{\circ} \mathrm{W}-0^{\circ}\right)$ (dashed, see text), and river flows (stars, see text). The PC 1 curve is the same as in Fig. 8. The SST curve is RCs $2-3$ of an SSA with $M=25 \mathrm{yr}$ applied to the GISST data multiplied by -1 . The riverflow curve is RCs 2-3 of an SSA with $M=30 \mathrm{yr}$ applied to JFM means of Paraná/Paraguayminus- Uruguay/Negro River discharge. The amplitudes of each curve are arbitrary and have been scaled to appear similar. 
calized region of net descent to the southwest. In the negative phase of PC 1, however, the SACZ is almost absent, with broad ascent covering nearly all of tropical and subtropical South America.

On submonthly timescales, Liebmann et al. (1999) found that intensified SACZ episodes are accompanied by a trough to the southwest that is produced by a transient Rossby wave train from higher southern latitudes. The interannual SACZ/trough structure in Fig. 3 may be a rectification of these intraseasonal events, that is, the product of random sampling of different numbers of submonthly events in any given summer. We find some supporting evidence for this view in a tendency for transient wave activity to be funneled into the anomalous descent region to the southwest of the SACZ during summers when the SACZ is intensified. The interannual variability in the SACZ found in our study is largely independent of ENSO, as seen in the lack of any characteristic correlations with tropical Pacific SSTs (Fig. 7a).

Kalnay and Halem (1981) identified a similar (though less localized) stationary Rossby wave in the lee of the Andes in 1979 from the First Global Atmospheric Research Program Global Experiment. Subsequent GCM experiments by Kalnay et al. (1986) indicated that this wave could exist independent of the Andes, but that tropical heating over either the Pacific or Atlantic sector could generate it.

Over the southwest Atlantic, SST anomalies are found to accompany the interannual intensifications of the SACZ, with negative anomalies north of about $40^{\circ} \mathrm{S}$ and positive ones to the south. The latter coincide with decreased westerly winds and are thus consistent in sign with the effect of reduced evaporation. The cold anomalies to the north partially underlie the cold atmospheric trough associated with the intensified SACZ; they thus also tend to be consistent with atmospheric forcing, both thermodynamically and through anomalous Ekman pumping (Kalnay et al. 1986). On the other hand, it is plausible that these latter negative SST anomalies may reinforce the overlying atmospheric trough. Thermal inertia in the upper ocean may tend to increase the persistence of SACZ anomalies through reduced thermal damping, amplifying the interannual anomalies over what would arise through purely random sampling of intraseasonal events (e.g., Bladé 1997). The SST dipole coincides with the Malvinas-Brazil current confluence region, suggesting a possible oceanic origin.

The regions of significant correlations between PC 1 and SST on interannual and interdecadal timescales are not identical. Over the South Atlantic, interdecadal anomalies north of $30^{\circ} \mathrm{S}$ predominate and extend toward the equator, while anomalies south of $30^{\circ} \mathrm{S}$ are near zero. These subtropical SST anomalies may exert a stronger influence on the SACZ. Results from recent experiments with an atmospheric GCM forced with observed Atlantic SSTs support this possibility (Robertson et al. 2000). On the other hand, the 40-yr time series is too short to conclusively reject the null hypothesis that the interdecadal "oscillation" arises from random sampling variations. The SST interdecadal correlations found here may be a result of atmospheric forcing. Further GCM experiments are needed to address the issue of any influence of South Atlantic SST anomalies on the atmosphere.

Venegas et al. (1997) have documented a 14-16-yr interdecadal component in broad-scale SSTs and sea level pressures over the South Atlantic. Their mode has a similar spatial structure in SST to Fig. 9 and an evolution similar to Fig. 10. A strengthening (weakening) of the subtropical anticyclone over the South Atlantic is found to accompany negative (positive) broad-scale SST anomalies there (Venegas et al. 1997). The interdecadal variability over South America found in our study may be a regional counterpart of this basin-scale variability. Although we find little evidence of remote teleconnections in SST, Venegas et al. suggest that their interdecadal mode may be part of the global-scale mode found by Mann and Park (1994). Variability on this timescale has also been found over the Pacific (Tanimoto et al. 1993; White and Cayan 1998) and Atlantic (Deser and Blackmon 1993; Moron et al. 1998; Tourre et al. 1999) Oceans.

The interdecadal component was found to be much stronger in the north-south gradient of streamflow anomalies than in the streamflows themselves examined by Robertson and Mechoso (1998). The Paraná/Paraguay rivers are directly influenced by the SACZ. The Uruguay/Negro rivers to the south are influenced in the opposite sense through the dipole in vertical motion and possibly by accompanying variations in southward moisture transport by the low-level jet east of the Andes. A quasi-biennial component is also evident. Together with the ENSO-related and near-decadal peaks isolated by Robertson and Mechoso (1998), these oscillatory streamflow components suggest useful regional climate predictability.

Acknowledgments. We wish to thank Kingtse Mo and Julia Paegle for helpful discussions. This work was supported by NOAA Grants NA86GPO289 and NA76GPO536. The NCEP-NCAR reanalysis data were provided through the NOAA Climate Diagnostics Center (http://www.cdc.noaa.gov/).

\section{REFERENCES}

Allen, M. R., and L. A. Smith, 1996: Monte Carlo SSA: Detecting irregular oscillations in the presence of colored noise. J. Climate, 9, 3373-3404.

Bladé, I., 1997: The influence of midlatitude ocean-atmosphere coupling on the low-frequency variability of a GCM. Part I: No tropical SST forcing. J. Climate, 10, 2087-2106.

Casarin, D. P., and V. E. Kousky, 1986: Anomalias de precipitaco no sul do Brasil e variacões na circulacoes atmosférica. Rev. Brasil. Meteor., 1, 83-90.

Davis, R. E., 1976: Predictability of sea surface temperature and sea 
level pressure over the North Pacific. J. Phys. Oceanogr., 6, 249-266.

Deser, C., and M. L. Blackmon, 1993: Surface climate variations over the North Atlantic Ocean during winter: 1900-1989. J. Climate, 6, 1743-1754

Dettinger, M. D., C. M. Strong, W. Weibel, M. Ghil, and P. Yiou, 1995: Software for singular spectrum analysis of noisy time series. Eos, Trans. Amer. Geophys. Union, 76 (2), 12, 14, 21.

Gandu, A. W., and P. L. Silva Dias, 1998: Impact of tropical heat sources on the South American tropospheric upper circulation and subsidence J. Geophys. Res., 103, 6001-6015.

Genta, J. L., G. Perez-Iribarren, and C. R. Mechoso, 1998: A recent increasing trend in the streamflow of rivers in southeastern South America. J. Climate, 11, 2858-2862.

Gill, A. E., 1980: Some simple solutions for heat-induced tropical circulation. Quart. J. Roy. Meteor. Soc., 106, 447-462.

Hoskins, B. J., and D. J. Karoly, 1981: The steady linear response of a spherical atmosphere to thermal and orographic forcing. $J$. Atmos. Sci., 38, 1179-1196.

—, I. N. James, and G. H. White, 1983: The shape, propagation and mean-flow interaction of large-scale weather systems. $J$. Atmos. Sci., 40, 1595-1612.

Kalnay, E., and M. Halem, 1981: Large amplitude stationary Rossby waves in the Southern Hemisphere. Proc. Int. Conf. Early Results of FGGE and Large Aspects of its Monsoon Experiments, Tallahassee, Florida, ICU/WMO, 3.5-3.15.

_ K. C. Mo, and J. Paegle, 1986: Large-amplitude, short-scale stationary Rossby waves in the Southern Hemisphere: Observations and mechanistic experiments to determine their origin. J. Atmos. Sci., 43, 252-275.

— , and Coauthors, 1996: The NECP/NCAR 40-year reanalysis project. Bull. Amer. Meteor. Soc., 77, 437-470.

Kiladis, G. N., 1998: Observations of Rossby waves linked to convection over the eastern tropical Pacific. J. Atmos. Sci., 55, 321355.

_ , and K. M. Weickmann, 1992: Extratropical forcing of tropical Pacific convection during northern winter. Mon. Wea. Rev., 120, 1924-1938.

— , and — 1997: Horizontal structure and seasonality of largescale circulations associated with submonthly tropical convection. Mon. Wea. Rev., 125, 1997-2013.

Kodama, Y.-M., 1992: Large-scale common features of subtropical precipitation zones (the Baiu frontal zone, the SPCZ, the SACZ) Part I: Characteristics of subtropical frontal zones. J. Meteor. Soc. Japan, 70, 813-835.

_ 1993 : Large-scale common features of subtropical precipitation zones (the Baiu frontal zone, the SPCZ, the SACZ). Part II: Conditions of the circulations for generating the STCZs. J. Meteor. Soc. Japan, 71, 581-610.

Li., Z. X., and H. Le Treut, 1999: Transient behavior of the meridional moisture transport across South America and its relation to atmospheric circulation patterns. Geophys. Res. Lett., 26, 1409 1412.

Liebmann, B., and C. A. Smith, 1996: Description of a complete (interpolated) outgoing longwave radiation dataset. Bull. Amer. Meteor. Soc., 77, 1275-1277.

, G. N. Kiladis, J. A. Marengo, T. Ambrizzi, and J. D. Glick,
1999: Submonthly convective variability over South America and the South Atlantic Convergence Zone. J. Climate, 12, 18771891.

Mann, M. E., and J. Park, 1994: Global-scale modes of surface temperature variability on interannual to century timescales. J. Geophys. Res., 99 (D12), 25 819-25 833.

, and J. M. Lees, 1996: Robust estimation of background noise and signal detection in climatic time series. Climatic Change, 33, 409-445.

Moron, V., R. Vautard, and M. Ghil, 1998: Trends, interdecadal and interannual oscillations in the global sea-surface temperature. Climate Dyn., 14, 545-569.

Nogués-Paegle, J., and K. C. Mo, 1997: Alternating wet and dry conditions over South America during summer. Mon. Wea. Rev., 125, 279-291.

Olson, D. B., G. P. Podestá, R. H. Evans, and O. B. Brown, 1988: Temporal variations in the separation of Brazil and Malvinas currents. Deep-Sea Res., 15, 1971-1990.

Pisciottano, G., A. Diaz, and G. Cazes, 1994: El Niño-Southern Oscillation impact on rainfall in Uruguay. J. Climate, 7, 12861302.

Rayner, N. A., C. K. Folland, D. E. Parker, and E. B. Horton, 1995: A new global sea-ice and sea surface temperature (GISST) data set for 1903-1994 for forcing climate models. Hadley Centre Internal Note 69, 13 pp. [Available from Meteorological Office, London Road, Bracknell RG12 2SY, United Kingdom.]

Robertson, A. W., and C. R. Mechoso, 1998: Interannual and decadal cycles in river flows of southeastern South America. J. Climate, 11, 2570-2581.

- - — temperature anomalies on the North Atlantic Oscillation. J. Climate, 13, 122-138.

Rodwell, M. J., and B. J. Hoskins, 1996: Monsoons and the dynamics of deserts. Quart. J. Roy. Meteor. Soc., 122, 1385-1404.

Ropelewski, C. F., and M. S. Halpert, 1987: Global and regional scale precipitation associated with El Niño/Southern Oscillation. Mon. Wea. Rev., 115, 1606-1626.

— , and — 1996: Quantifying Southern Oscillation-precipitation relationships. J. Climate, 9, 1043-1059.

Sardeshmukh, P. D., and B. J. Hoskins, 1987: On the derivation of the divergent flow from the rotational flow: The chi problem. Quart. J. Roy. Meteor. Soc., 113, 339-360.

Tanimoto, Y., N. Iwasaka, K. Hanawa, and Y. Toba, 1993: Characteristic variations of sea surface temperature with multiple time scales in the north Pacific. J. Climate, 6, 1153-1160.

Tourre, Y. M., B. Rajagopalan, and Y. Kushnir, 1999: Dominant patterns of climate variability in the Atlantic ocean region during the last 136 years. J. Climate, 12, 2285-2299.

Vautard, R., P. Yiou, and M. Ghil, 1992: Singular spectrum analysis: A toolkit for short, noisy, chaotic signals. Physica D, 58, 95126.

Venegas, S. A., L. A. Mysak, and D. N. Straub, 1997: Atmosphereocean coupled variability in the South Atlantic. J. Climate, 10, 2904-2920.

White, W. B., and D. R. Cayan, 1998: Quasi-periodicity and global symmetries in interdecadal upper ocean temperature variability. J. Geophys. Res., 103, 21 335-21354. 